\title{
Radical vulvectomy for a rare case of squamous cell carcinoma vulva: a case report
}

\author{
Kirty Nahar ${ }^{1 *}$, Nikita Nahar ${ }^{2}$ \\ ${ }^{1}$ Department of obstetrics and Gynaecology, Apollo Hospitals International Ltd., Ahmedabad, Gujarat, India \\ ${ }^{2}$ Smt NHL Municipal Medical College, Ahmedabad, Gujarat, India
}

Received: 25 June 2021

Accepted: 20 July 2021

\section{*Correspondence:}

Dr. Kirty Nahar,

E-mail: naharkirty@yahoo.co.in

Copyright: (C) the author(s), publisher and licensee Medip Academy. This is an open-access article distributed under the terms of the Creative Commons Attribution Non-Commercial License, which permits unrestricted non-commercial use, distribution, and reproduction in any medium, provided the original work is properly cited.

\begin{abstract}
Cancer of the vulva is the fourth most common malignancy of the female genital tract. Vulvar carcinoma is a rare and aggressive gynecological malignancy. It affects elderly females, with the mean age at diagnosis being 55-60 years. Regional metastasis to inguinal lymph nodes is common. There is a high incidence of pelvic node involvement, especially in those with pathologically positive inguinal nodes. Surgery appears to be the only curative treatment option in the early stages of the disease. But in most patients, surgery is associated with considerable morbidities and psychosexual issues. Hence, in the quest for a less morbid form of treatment, multimodality approaches with various combinations of surgery, chemotherapy, and radiation therapy have been suggested for advanced vulvar cancers. Due to the low incidence of the disease, the level of evidence for the success of these treatment modalities is poor. Mrs. X, a 54-year-old female, P2L2 A0 presented at Apollo hospitals, Ahmedabad with a giant vulvar tumor of about 8x7 cm in size arising from anterior half of vulva involving clitoris and both labia minora. The vulval growth was initially small and had attained present size in last 15 days. She had complaints of postmenopausal bleeding per vaginum for 8 days, foul smelling discharge and itching vulva on and off for 1 month. Biopsy revealed moderate to well differentiated squamous cell carcinoma (SCC). MRI pelvis with contrast found suspicious lymph node in bilateral iliac vessel region and bilateral inguinal region. She underwent radical vulvectomy with bilateral inguinal lymph node dissection, and bilateral pelvic lymph node dissection. Early diagnosis, timely intervention and prompt surgical management could save the patient's life. Histopathological report showed well differentiated SCC of vulva with no lymphnodes involvement. Depth of tumor was $12 \mathrm{~mm}$ and there was no lymphovascular and perineural invasion. All surgical margins and base of growth were free of tumor. According to TNM stabilization patient had SCC vulva stage IB (T1bN0M0). This patient was disease free after 18 months of follow-up. Vulvar cancer incidence is significantly high in postmenopausal and multiparous women. The most important prognostic factors are tumor stage and lymph node status. Oncological resection should be equated with functional outcome. The multidisciplinary team approach should be sought for this rare gynecological malignancy.
\end{abstract}

Keywords: Vulval carcinoma, SCC, Radical vulvectomy, Inguinal lymph node dissection

\section{INTRODUCTION}

Vulvar cancer is the fourth gynecologic malignancy among women worldwide, which usually affects elderly patients, with an estimated incidence of 2 newly diagnosed cases in 100.000 women every year. ${ }^{1-5}$ Vulvar cancer represents $5 \%$ of all tumours of the female genital tract,
$95 \%$ of them are SCC, the rest $5 \%$ being melanomas, sarcomas and basal cell carcinomas. ${ }^{6}$

This is more prevalent in post-menopausal multiparous women. The increased age is itself a high-risk factor. The most common symptoms are pruritus, ulcer, vaginal discharge, or pain. Diagnosis is inferred by vigilant 
history, clinical examinations, vulvar biopsy, and/or diagnostic imaging.

About $43 \%$ of vulvar carcinomas are due to human papilloma virus (HPV). ${ }^{7}$ HPV 16 and 33 are the predominant subtypes, accounting for $55.5 \%$ of all HPVrelated vulvar cancers. More than $60 \%$ of all vulvar cancers occur in the more developed nations. There are 2 distinct histological patterns of squamous cell vulvar carcinomas, with 2 different risk factor profiles. 1) The basaloid/warty lesions are more common in young women, being commonly associated with HPV DNA (75-100\%). This subtype simulates the risk factor profile of cervical cancer. 2) The keratinizing vulvar carcinomas represent the majority of the vulvar lesions $(>60 \%)$. They occur more often in older women and are rarely associated with HPV. ${ }^{8}$ The other different less common histologies are melanoma, basal cell, Bartholin gland adenocarcinoma, sarcoma, and Paget's disease. The risk of developing vulvar carcinoma is related to different behavioral, reproductive, hormonal, and genetic aspects. Factors that increase the risk include other genital cancers, chronic inflammatory diseases of the vulva, smoking, history of genital warts, and vulvar intraepithelial neoplasia.

Vulvar SCC, in first stages has a horizontal growth with invasion in adjacent organs like vagina, urethra or anus followed by lymphatic spreading to regional lymph nodes (inguinal, femoral and pelvic). In advanced cases, distant metastases might be also present in liver, lungs or bones. ${ }^{5}$ Prognostic factors are considered the size of the lesion, the depth of invasion and the disease stage. ${ }^{1}$ Primary treatment consists in wide surgical excision associated, if necessary, with regional lymphadenectomy. Radiotherapy and chemotherapy are also recommended in particular cases. ${ }^{1}$

The staging of vulvar cancer is popularly done according to the international federation of gynecology and obstetrics (FIGO). ${ }^{9}$ Lymph node positivity is independent bad prognostic factor. ${ }^{9}$ According to disease's stage, 5 years survival rates range from $86 \%$ for early-stage disease (FIGO stage I)-19\% for metastatic disease (FIGO stage IVB) life-time risk of developing vulvar cancer is $0.3 \% .^{10}$

Due to the rarity of the cancer and lack of randomized trials, management of this aggressive disease is shrouded with dilemmas and controversies. Although surgery has remained the cornerstone in the management of vulvar carcinoma, especially in the early stages, the morbidities associated cannot be overlooked. This has led to changing paradigms in the surgical management from the mutilating radical en bloc procedures to triple incision techniques to the present radical local excisions, mainly to maintain the sexual identity and satisfactory body image of the affected patient, and to decrease surgery-associated morbidity. ${ }^{11}$

\section{CASE REPORT}

Mrs. X, a 54-year-old female, P2L2 A0 came in gynecological out patient department of Apollo hospitals,
Ahmedabad on 11.03.19. She presented with complaints of postmenopausal bleeding on and off for 8 days, foul smelling discharge and itching vulva on and off since onemonth, small growth felt at vulva for 4 months, which increased in size to giant vulval tumor of about $8 \times 7 \mathrm{~cm}$ in last 15 days.

\section{Obstetric history}

P2L2A0: 2 full term normal delivery-2 male child-alive and healthy. Last delivery was 27 years back.

\section{Menstrual history}

Menopause 13 years back.

\section{Past history}

Known case of hypertension since last 10 years, was on tab Betatrop (atenolol $50 \mathrm{mg}$ and nifedipine $20 \mathrm{mg}$ ) 1 tablet daily.

\section{Family history}

Not contributory. Patient was admitted at Apollo hospitals on 11.13.19 for further management.

\section{On examination}

Patient was thin built, weight- $65 \mathrm{~kg}$, height- $156 \mathrm{~cm}$, pallarnil, pedal oedema-nil, lymph nodes-nil, P-78/min, BP$110 / 70 \mathrm{mmHg}$, temperature-98.2 ${ }^{0} \mathrm{~F}$, CVS-S1S2 normal, RS-RR-18/min, chest clear.

Per abdomen examination-soft, inguinal nodes-not palpable.

On local examination-cauliflower warty growth, sessile and hard in consistency about $8 \times 7 \mathrm{~cm}$ arising from anterior half of vulva involving clitoris and both labia minora, foul smelling pus discharge present, small ulcerative growth present on right labia underneath the big growth. Growth is about $0.5 \mathrm{~cm}$ away from urethral meatus. Posteriorly a patch of lichen sclerosis seen on vulva, vagina normal.

Bimanual examination: cervix healthy, uterus anteverted anteflexed, normal size, firm, mobile and fornices free.

Investigations-On 11.03.19: haemoglobin ( $\mathrm{Hb})-11 \mathrm{gm} \%$, white cell count-9,260/ cu mm, differential count (DC)-N $71 \%$, L 20\%, M 5\%, E 4\%, platelets-4,13,100/cumm, urine routine pus cells- $8-10 / \mathrm{hpf}, \mathrm{RBC}-12-15 / \mathrm{hpf}$, prothrombin time (PT)-12 sec (T), $11.1 \mathrm{sec}(\mathrm{C})$, international normalized ratio (INR)-1.08, activated partial thromboplastin time (APTT) -25.2 seconds, serum urea-42 $\mathrm{mg} / \mathrm{dl}$, serum creatinine- $0.73 \mathrm{mg} / \mathrm{dl}$, blood group-B positive, serum sodium-139 $\mathrm{mmol} / \mathrm{L}$, serum potassium$3.32 \mathrm{mmol} / \mathrm{L}$, serum chloride-100.6 mmol/L, serum glutamic-Pyruvic transaminase (SGPT)-12.4 U/L, human immunodeficiency virus (HIV) and surface antigen of 
hepatitis B virus (HBsAg)-nonreactive, Pap's smear (cervical)-negative for intraepithelial lesion or malignancy.

A clinical diagnosis of giant vulvar tumor? Vulvar carcinoma was made. She underwent Examination under anaesthesia and biopsy from vulvar growth under general anesthesia on 11.03.19. Biopsy report showed moderate to well differentiated SCC (Figure 1, 2).

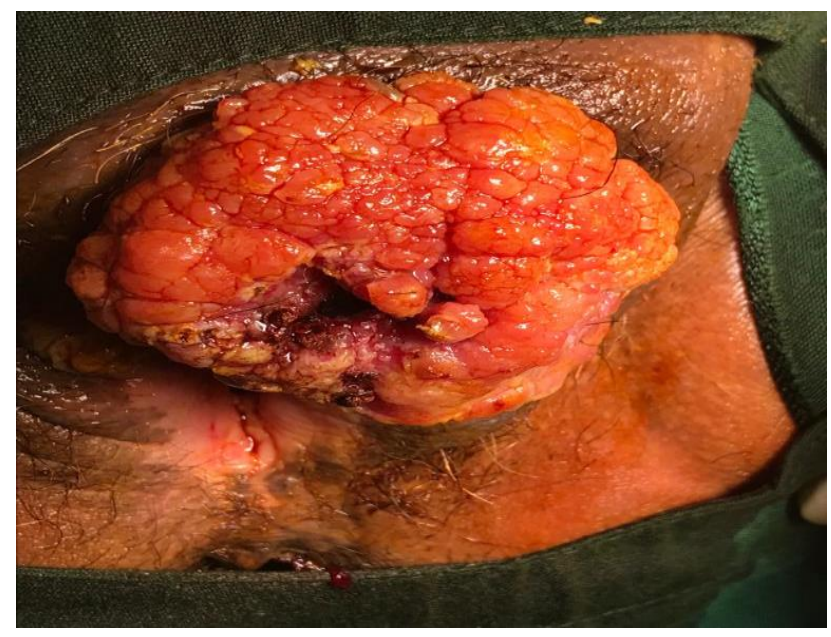

Figure 1: Biopsy taken-giant vulval tumor.

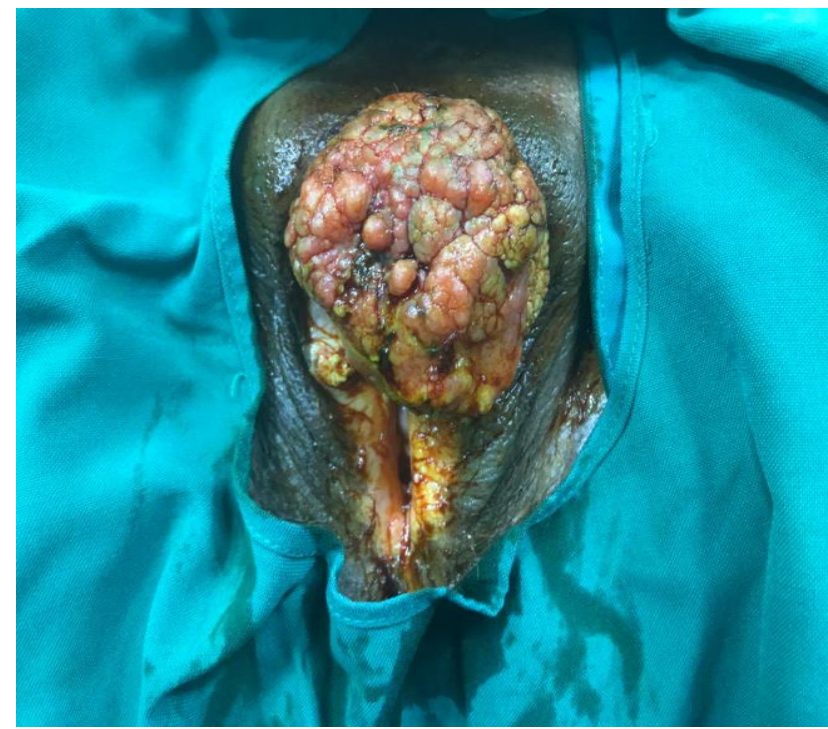

Figure 2: Preoperative aspect, giant vulval tumor.

MRI pelvis with contrast done on 12.03.19, showed a large intense heterogeneously enhancing lesion in vulva predominantly involving clitoris, both labia minora with significant surrounding fat stranding and enhancement of subcutaneous plane of pelvis and mild overlying skin thickening. Multiple enlarged lymph nodes were seen in inguinal region and along the external and internal iliac vessels on both sides, left more than right. Larger ones measures 19x18x11 mm along the left internal iliac vessels, $33 \times 13$ along right iliac vessels, $15 \times 12 \times 12 \mathrm{~mm}$ in left inguinal region, $12 \times 12 \times 9 \mathrm{~mm}$ in right inguinal region.
Considering the size and the tumor's aggressivity, patient underwent radical vulvectomy, bilateral inguinal lymph node dissection and bilateral pelvic lymph node dissection under general anaesthesia on 13.03.19. While performing Radical vulvectomy $1.5 \mathrm{~cm}$ safe margin was kept all around the growth in order to minimize local recurrence. Anteriorly the vulval growth was in close proximity to anterior margin of urethra, hence growth was carefully dissected preserving the urethra (Figure 3, 4).

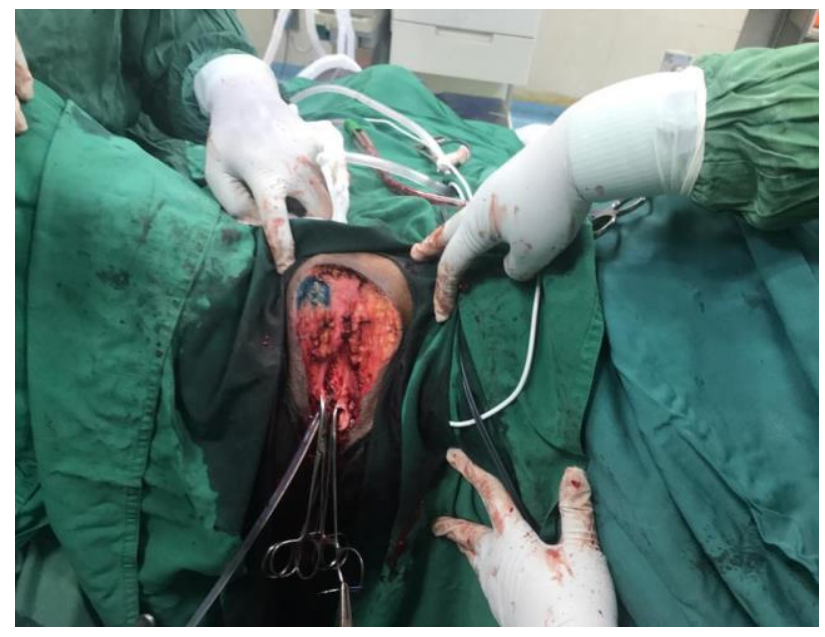

Figure 3: Defect after radical vulvectomy.

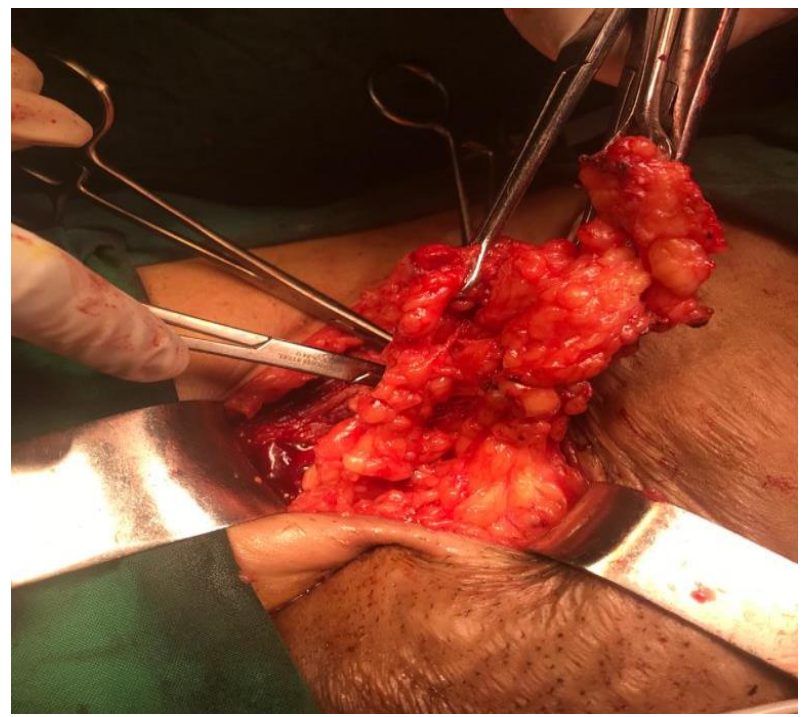

Figure 4: Inguinal lymph node dissection.

The patient made a good postoperative recovery. Abdominal and vulval dressing done with drain removal on $6^{\text {th }}$ post-op day, wound was healthy (Figure 5, 6). Histopathological examination showed warty proliferation of dyskeratotic cells, squamous pearls, cellular and keratin debris with dense lymphoplasmacytic stromal response. The diagnosis revealed squamous cell carcinoma, well differentiated (G1) warty type measuring $6 \times 5 \times 3 \mathrm{~cm}$ involving right and left vulva with no inguinal and no pelvic lymph node involvement. Depth of tumor was 12 $\mathrm{mm}$ with infiltrating pattern of growth. Lymphovascular 
and perineural invasion not seen. All Surgical margins and base of growth were free of tumor. According to TNM stabilization our patient had vulvar squamous cell carcinoma stage IB (T1bN0M0). P16 by IHC was negative. (clone-mouse monoclonal antibody G17- 405, biogenex). This clone was reactive for HPV type $16,18,31,33,52,58$.

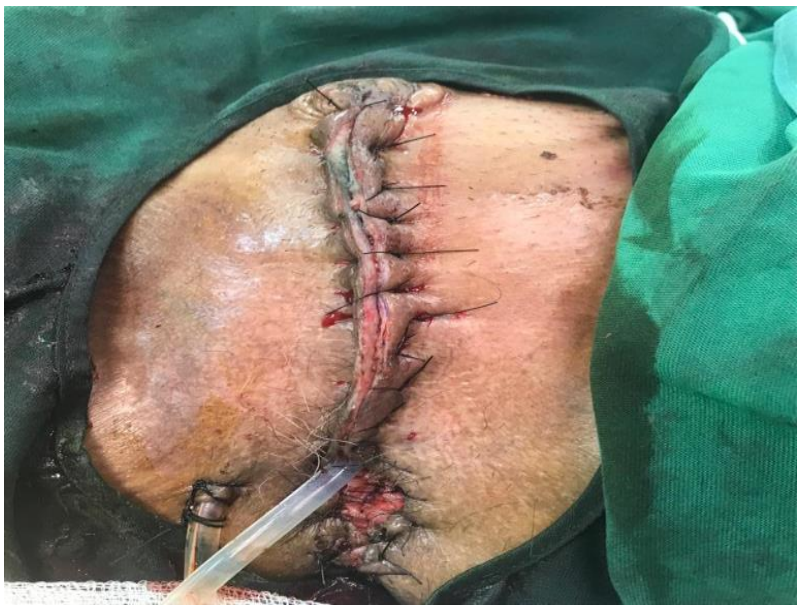

Figure 5: Radical vulvectomy-post-operative aspect.

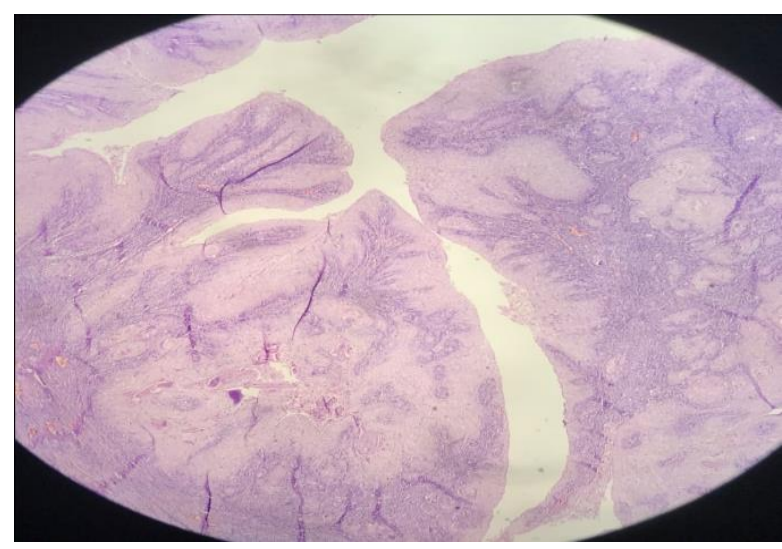

Figure 6: Mucosal invasion of squamous cell carcinoma with good differentiation (G1), HE staining (10 X).

Patient managed with injection Zostum (Sulbactum and cefoperazone) 2 gram I/V 12 hourly and injection Metrogyl I/V 8 hourly for 5 days, followed by tab Cefuroxime $500 \mathrm{mg}$ twice daily for 5 days. Inj clexane (enoxaparine sodium) $0.4 \mathrm{mg}$ subcutaneously given for 3 days postoperatively. Dressing of vulval wound done daily. As her haemoglobin was $9.3 \mathrm{gm} \%$, she was given I/V Iron sucrose $200 \mathrm{mg}$ on 22.03.19. Reference was done to Oncologist and he advised external radiation after 3 weeks in view of large tumor size Patient was discharged with stable hymodynamics on 22.03.19.

On follow up, her sutures were removed on 29.03.19. Skin necrosis was observed on left inguinal region below the suture line. Ultrasound was done and it showed $3.3 \times 0.8 \mathrm{~cm}$ size echogenic area in subcutaneous tissue in left inguinal region suggestive of pus/haematoma. There was wound gaping about size $7 \times 2 \mathrm{~cm}$ due to skin necrosis in left inguinal region which required alternate day dressing of wound. Skin necrosis about $2 \times 2 \mathrm{~cm}$ also developed in right inguinal region below the suture line. This was managed by dressing and antibiotics and wound re-suturing was done in bilateral inguinal region under general anaesthesia on 16.04.19 (Figure 7-10).

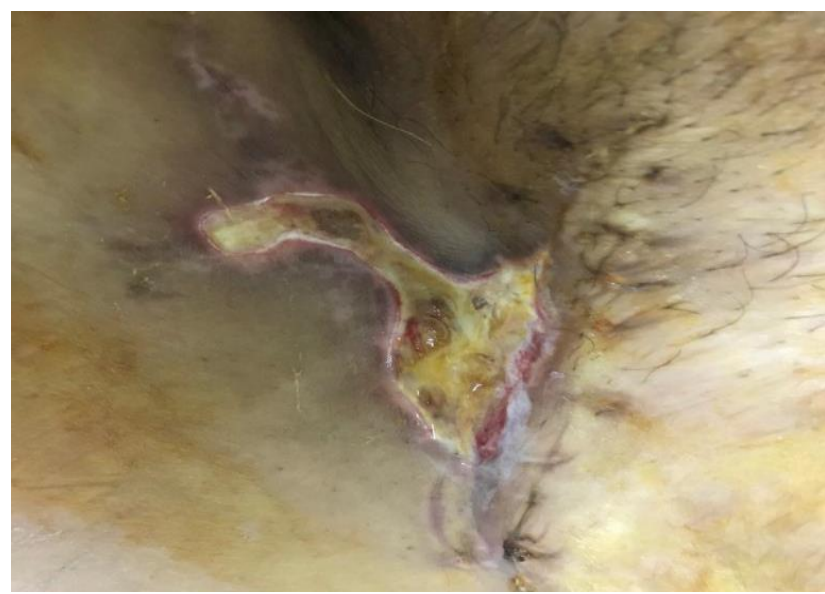

Figure 7: Skin necrosis in left inguinal region.

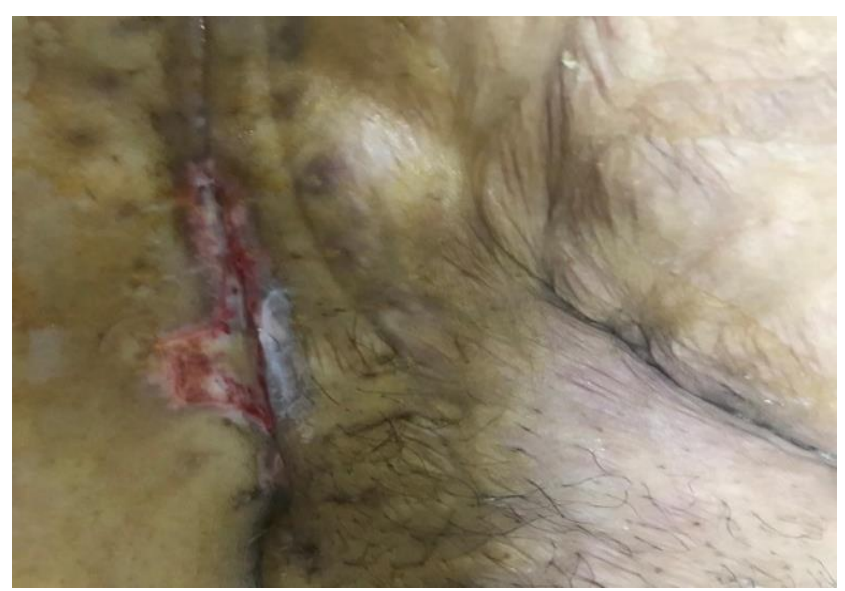

Figure 8: Skin necrosis in right inguinal region.

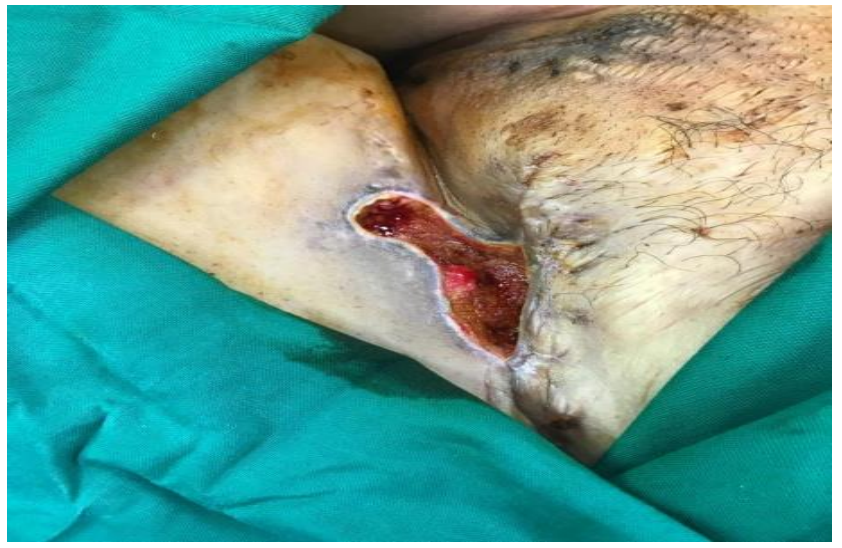

Figure 9: Wound, healthy granulation tissue before re-suturing. 


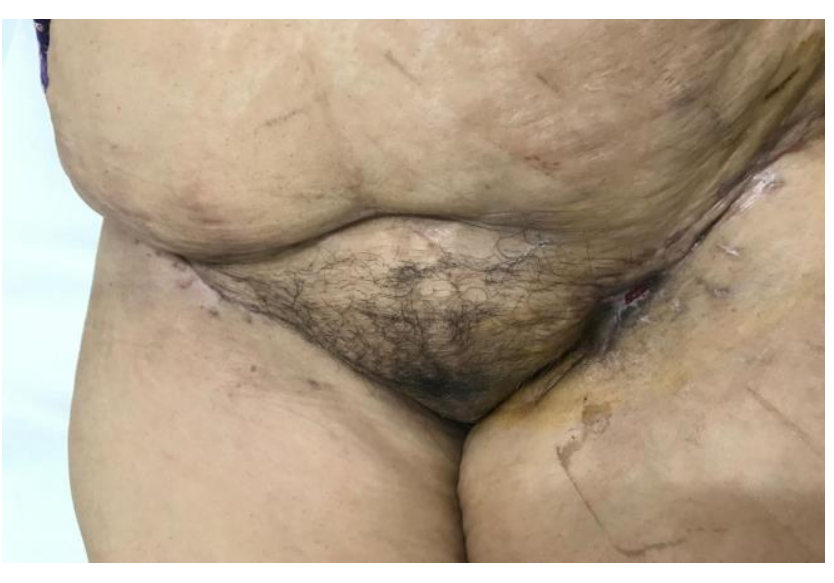

Figure 10: End result, 5 weeks post-surgery.

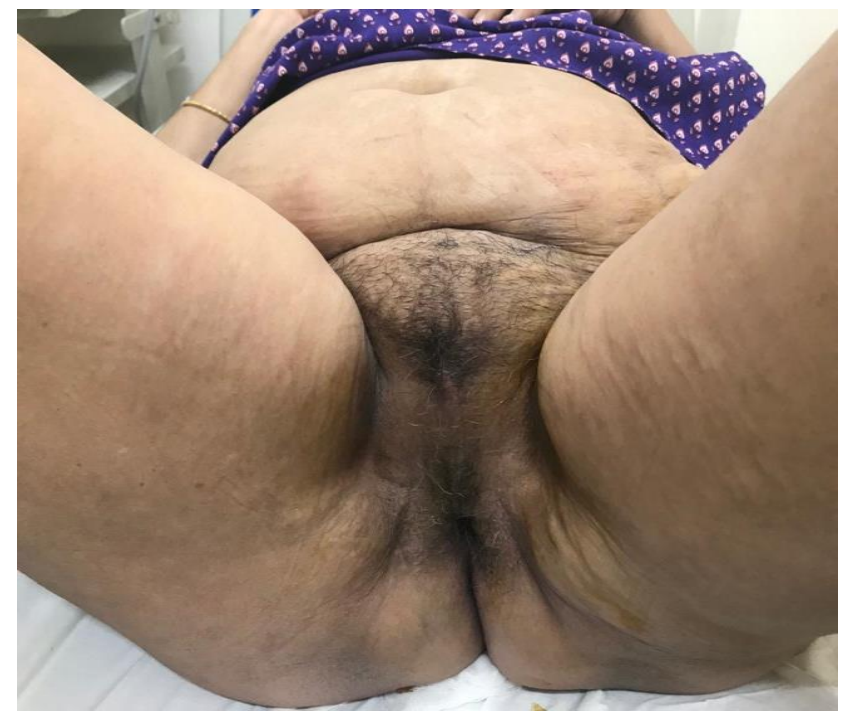

Figure 11: End result of radical vulvectomy, B/L inguinal lymphadenctomy and $B / L$ pelvic lymphadenectomy: 5 weeks post-surgery.

On follow up after 2 months, patient was well, showed no evidence of local recurrence or pelvic metastasis. MRI pelvis with contrast was done on 27.06.20 showed plaque like soft tissue thickening at the level of vulva, introitus and bilateral inguinal stations, likely scar tissue related to surgical history, no locally residual or re-currant disease. No enlarged lymph nodes. Vagina, cervix, uterus and both ovaries normal. Hence patient did not require radiotherapy. She was followed up every 3 months for 1 year and later on every 6 months and she is well with no re-currrance of disease after 1 year 6 months of surgery.

\section{DISCUSSION}

Vulvar cancer is a rare and aggressive disease that affects especially elderly women. The incidence of SSC in the general population is $1-2 / 100,000$ women per year, while in women older than 75 years this rate is 10 -fold higher. 12,13 The prognosis is favorable when it is diagnosed in an early stage with a five-year survival rate of 80 to $90 \% .{ }^{14}$ Squamous cell carcinoma is the most common histology of vulvar cancer. Other less common histological subtypes are extramammary Paget's disease, melanoma, Bartholin's gland tumors, adenocarcinoma, and basal cell carcinoma. ${ }^{12}$

The majority of the patients present in the advanced stage in developing countries due to social stigma, low to middle socioeconomic status, low literacy rate, logistic issues, poor screening program, and insufficient awareness about the disease. Public awareness of warning symptoms of vulvar malignancy may help in early detection and cure.

The incidence of vulvar carcinoma has a bimodal peak. ${ }^{15}$ Currently, development of vulvar carcinoma in situ in young women is suggested to correlate to human papillomavirus (HPV) infection. In older women, the etiology of the carcinoma is attributed to chronic irritation or other poorly understood cofactors. The incidence of vulvar carcinoma in situ and vulvar carcinoma is higher in women with multiple sexual partners and in women with a history of HPV infection. For women who report a history of genital warts or HPV-related disease, the relative risk for carcinoma in situ is 18.5 and for invasive cancer is 14.5. ${ }^{15}$ Certain strains of HPV are known to be more oncogenic than others. HPV types $16,18,31,33,35,45$, and 54 are more likely to be associated with cervical neoplasia and cancer and are suspected to also be responsible for vulvar cancers. ${ }^{15}$ The DNA from HPV 16 and 18 has been detected in up to $60 \%$ of patients with vulvar cancer. ${ }^{15}$ In our case, although the Vulval tumor was warty type, it was not associated with HPV DNA as p16 by IHC was negative.

Vulvar cancer is an aggressive gynecological malignancy, with regional metastasis to the inguinal lymph nodes being common with this condition. ${ }^{16}$ No large randomized controlled trials or meta-analysis because of rarity of disease. So, treatment guidelines are based on small retrospective individual center-based studies in literature.

The golden standard in treating vulvar cancer remains in achieving a good local control of the disease which seems to be best obtained when ontogenic principles of anatomy are entirely respected. ${ }^{17,20}$

Current surgical treatment for vulvar cancer consists in the wide resection of the tumor with negative resection margins (at least $2 \mathrm{~cm}$ from the macroscopic tumor borders) without involving any deeper tissues, with perprimam suture of the wound associated with inguinal lymph node dissection. ${ }^{17,18}$ However, if after resection histopathological examination reveals the presence of positive resection margins, adjuvant radiation therapy might be needed. ${ }^{18,21}$ When it comes to the most appropriate incision to perform a total vulvectomy with bilateral groin lymph node dissection, initially it was thought that a unique incision for the three therapeutic gestures is enough; however the local complications including leg oedema or wound dehiscence were very often seen, so a triple butterfly incision was proposed with better results in terms of local healing and postoperative 
complications. ${ }^{17,19,20}$ Some authors recommend that the deep resection margin should be the inferior surface of the uro-genital diaphragm and the fascia covering pubic symphysis. $^{21-23}$

Five year overall survival rates range between $70-91 \%$ for cases with negative inguinal lymph nodes and $25-41 \%$ for cases with positive nodes; however, in cases with positive inguinal lymph nodes, pelvic lymph node dissection might be needed due to the fact that up to $20 \%$ of patient with positive groin lymph nodes will report positive pelvic nodes. ${ }^{24-28}$ In this case we performed radical vulvectomy, bilateral inguinal lymph node and bilateral pelvic lymph node dissection giving a triple butterfly incision.

In our study, as the tumor was of giant size and the preoperative imaging evaluation by MRI pelvis, suggested suspicious lymph node metastasis, hence we performed bilateral inguinal lymph node and bilateral pelvic lymph node dissection as well.

There are some characteristics of squamous cell carcinoma that influence the prognosis such as differentiation grades, location, tumour size, depth and perineural invasion.Our patient presented with well differentiated squamous cell carcinoma (G1) that has a good prognosis compared with stages 3 and 4 that recur and metastasize faster. ${ }^{14}$ In general, the Squamous cell carcinoma located in the genital region are considered high risk and those in the vulvar area require special attention of the treatment due to the aggressiveness. ${ }^{29}$

The size of the lesion is also important in risk assessment. Squamous cell carcinoma larger than $2 \mathrm{~cm}$ are more likely to recur and metastasize than those

with a diameter of less than $2 \mathrm{~cm}$. In our case, the patient had giant vulval tumor of size $8 \times 7 \mathrm{~cm}$ and it was aggressive and had attained the present size within a span of 15 days.

The thickness of the tumour is considered one of the most important factors, suggesting that a depth bigger than 6 $\mathrm{mm}$ have a higher risk for

lymph node involvement and a rate of metastasis of $15 \% .{ }^{30}$ In the case above, the histopathological examination showed a thickness of $12 \mathrm{~mm}$, but there was no regional lymph node involvement. Risk factors for lymph node metastasis include also age, degree of differentiation, tumour stage, presence of capillary-lymphatic space invasion. Almost $30 \%$ of patients with operable disease have lymph nodal extension. ${ }^{30}$

Perineural invasion, known as neurotropism, is described as tumour cells in the perineural space. ${ }^{31}$ It is a poor prognostic factor ${ }^{29}$ but perineural space was not involved in our patient. Also, there was no lymphovascular invasion in our case. The staging of this type of skin cancer can be realized using American joint committee on cancer classification (AJCC with TNM) or the 2009 international Federation of Gynecology and Obstetrics classification (FIGO). The information required are the dimension and extent of the tumour $(\mathrm{T})$, node status $(\mathrm{N})$ and presence of distant metastasis (M). The case that we reported presented a tumour size of more than $2 \mathrm{~cm}$ and it had grown more than $1 \mathrm{~mm}$ (0.04 inches) into underlying tissue (stroma) (T1b), no spread to the regional lymph nodes (N0) with no distant metastasis (M0) that was classified as stage IB according to AJCC and FIGO classifications. ${ }^{6,32}$ In our case radical vulvectomy was necessary considering the tumour size. Separate incisions were given for inguinal lymphadenectomy, hence the triple butterfly incision.

Adjuvant radiotherapy is recommended in high-risk cases with tumour size over $4 \mathrm{~cm}$, lymphovascular invasion, lymph node invasion and close or positive surgical margins. ${ }^{33}$ Radiotherapy of the inguinal region is also indicated in patients that have only an invaded lymph node. ${ }^{6}$ In our patient, as MRI pelvis with contrast after 2 months of surgery did not show any lymph node involvement or any residual disease, hence adjuvant radiotherapy was not required.

Prognosis is relatively good in early stages, the most important factor, like in breast cancer, being the presence of regional lymph nodes metastasis. ${ }^{34}$ The 5 -year survival rate is $70-90 \%$ for patients with negative nodes compared to $25-41 \%$ for those with lymph nodes metastasis. Other negative prognostic factors are perineural invasion, stage and older age. Considering FIGO classification, our patient has a 5-year survival rate of $86 \%$. Recurrences are more difficult to treat and can lead to distant metastasis. ${ }^{35,36}$

\section{CONCLUSION}

Vulvar cancer is a rare gynecological cancer, with a median age of 55 years and a peak incidence in fifthseventh decades. It is an aggressive cancer having a disabling effect on women, lowering their quality of life by deforming the perineal area that can affect their relationships, body image and confidence. Prevention followed by early detection and histological examination of any suspect vulvar lesions makes possible vulvar cancer detection in the first stages decreasing the morbidity and mortality.

Current therapeutic options for tumors involving external female genital tract include radical resections based on ontogenetic principles of anatomy in order to provide a good local control of the disease. In cases presenting with large tumors a bilateral inguinal lymph node dissection should be applied to impede tumor spread via lymphatic channels; a more advanced lymph node dissection including pelvic lymph node should be performed only in selected cases with high probability of positive nodes. In cases diagnosed with large surface tumors in which a simple wound closure is not possible, surgical reconstructions using flap insertion might be needed. In 
our case, although a giant vulvar tumor was encountered, per-primam simple wound closure was possible due to exophitic development of the tumor.

The multimodality treatment approach should be followed for an advanced case of vulvar cancer. Disease stage and lymph nodal positivity are the two most significant prognostic factors for survival in vulvar cancer.

Funding: No funding sources Conflict of interest: None declared

Ethical approval: Not required

\section{REFERENCES}

1. Judson PL, Habermann EB, Baxter NN, Durham SB, Virnig BA. Trends in the incidence of invasive and in situ vulvar carcinoma. Obstet Gynecol. 2006;107(5):1018-22.

2. Sturgeon SR, Brinton LA, Devesa SS, Kurman RJ. In situ and invasive vulvar cancer incidence trends (1973 to 1987). Am J Obstet Gynecol. 1992;166(5):1482-5.

3. Ansink AC, Heintz AP. Epidemiology and etiology of squamous cell carcinoma of the vulva. Eur J Obstet Gynecol Reprod Biol. 1993;48(2):111-5.

4. Coulter J, Gleeson N. Local and regional recurrence of vulval cancer: management dilemmas. Best Pract Res Clin Obstet Gynaecol. 2003;17(4):663-81.

5. Monaghan JM. The management of carcinoma of the vulva. In: Sheperd JH, Monaghan JM, editors. Clinical gynaecological oncology. $2^{\text {nd }}$ ed Oxford: Blackwell Scientific Publications. 1990;140-67.

6. Alkatout I, Schubert M, Garbrecht N, Weigel MT, Jonat W, Mundhenke C et al. Vulvar cancer: epidemiology, clinical presentation, and management options. Int J Womens Health. 2015;7:305-13.

7. De Martel C, Ferlay J, Franceschi S. Global burden of cancers attributable to infections in 2008: a review and synthetic analysis. Lancet Oncol. 2012;13(6):607-15.

8. Bruni L, Barrionuevo Rosas L, Albero G. ICO Information Centre on HPV and Cancer (HPV Information Centre) Human Papilloma virus and Related Diseases in India. Summary Report. 2017;27.

9. Gibb RK, Olawaiye AB, Chen LM. Vulva. In: Amin MB, editor. AJCC Cancer Staging Manual $8^{\text {th }}$ ed. Chicago: AJCC. 2017;633.

10. Cancer Stat Facts. Vulvar Cancer, The Surveillance, Epidemiology, and End Results (SEER) Program: National cancer institute. Available at: https://seer.cancer.gov/statfacts/html/vulva.html. Accessed on 2019 Aug 01.

11. Mitra S, Sharma MK, Kaur I, Khurana R, Modi KB et al. Vulvar carcinoma: dilemma, debates, and decisions. Cancer Manag Res. 2018;10:61-8.

12. Hacker NF, Eifel PJ, Van der Veldenc J. FIGO cancer report 2012. Cancer of the vulva. Int J Gynecol Obstet. 2012;119(2):S90-6.

13. Rauh-Hain JA, Clemmmer J, Clarke RM, Bradford LS, Growdon WB et al. Management and outcomes for elderly women with vulvar cancer overtime. BJOG. 2014;126(6):719-27.

14. Nooij LS, Brand FA, Gaarenstroom KN, Creutzberg CL, De Hullu JA, Van Poelgeest MI. Risk factors and treatment for recurrent vulvar squamous cell carcinoma. Crit Rev Oncol Hematol. 2016;106:1-13

15. Higgins RV. Surgical Treatment of Vulvar Cancer, Mediscape. Updated: 2016.

16. Mitra S, Sharma MK, Kaur I. Vulvar carcinoma: dilemma, debates, and decisions. Cancer Manag Res. 2018;10:61-8.

17. Hockel M, Schmidt K, Bornmann K, Horn LC, Dornhofer N. Vulvar field resection: novel approach to the surgical treatment of vulvar cancer based on ontogenetic anatomy. Gynecol Oncol. 2010;119(1):106-13.

18. De Hullu JA, Oonk MH, Van der Zee AG. Modern management of vulvar cancer. Curr Opin Obstet Gynecol. 2004;16(1):65-72.

19. Coulter J, Gleeson N. Local and regional recurrence of vulval cancer: management dilemmas. Best Pract Res Clin Obstet Gynaecol. 2003;17(4):663-81.

20. Stehman FB, Look KY. Carcinoma of the vulva. Obstet Gynecol. 2006;107(3):719-33.

21. Heaps JM, Fu YS, Montz FJ, Hacker NF, Berek JS. Surgical-pathologic variables predictive of local recurrence in squamous cell carcinoma of the vulva. Gynecol Oncol. 1990;38(3):309-14.

22. De Hullu JA, Hollema H, Lolkema S, Boezen M, Boonstra H, Burger MP et al. Vulvar carcinoma. The price of less radical surgery. 2002;95(11):2331-8.

23. Chan JK, Sugiyama V, Pham H, Gu M, Rutgers J, Osann K et al. Margin distance and other clinicopathologic prognostic factors in vulvar carcinoma: a multivariate analysis. Gynecol Oncol. 2007;104(3):636-41.

24. Miller B, Morris M, Levenback C, Burke TW, Gershenson DM. Pelvic exenteration for primary and recurrent vulvar cancer. Gynecol Oncol. 1995;58(2):202-5.

25. Thomas GM, Dembo AJ, Bryson SC, Osborne R, DePetrillo AD. Changing concepts in the management of vulvar cancer. Gynecol Oncol. 1991;42(1):9-21.

26. Cavanagh D. Vulvar cancer-continuing evolution in management. Gynecol Oncol. 1997;66(3):362-7.

27. Cavanagh D, Fiorica JV, Hoffman MS, Roberts WS, Bryson SC, LaPolla JP et al. Invasive carcinoma of the vulva. Changing trends in surgical management. Am J Obstet Gynecol. 1990;163(3):1007-15.

28. Gadducci A, Cionini L, Romanini A, Fanucchi A, Genazzani AR. Old and new perspectives in the management of high-risk, locally advanced or recurrent and metastatic vulvar cancer. Crit Rev Oncol Hematol. 2006;60(3):227-41.

29. Jecan CR, Raducu L, Filip I, Hernik D. A review of frequent cutaneous malignancies-part I: Nonmelanoma skin cancers. RoJCED. 2014;1(1):4651. 
30. Ross Rudolfph, Daniel E. Zelac. Squamous Cell Carcinoma of the Skin. Plast Reconstr Surg. 2004;114(6):82e-94.

31. Varsha B, Radhika M, Makarla S, Kuriakose MA, Kiran GS, Padmalatha G. Perineural invasion in oral squamous cell carcinoma: Case series and review of literature. J Oral Maxillofac Pathol. 2015;19(3):33541.

32. Bodean OM, Marcu RD, Spinu DA, Socea B, Diaconu $\mathrm{CC}$, Munteanu $\mathrm{O}$ et al. Pelvic floor disorders in gynecological malignancies. An overlooked problem? J Mind Med Sci. 2018;5(1):46-52.

33. Expert Panel on Radiation Oncology-Gynecology, Kidd E, Moore D, Varia MA, Gaffney DK, Elshaikh MA, Erickson B et al. Appropriateness Criteria ${ }^{\circledR}$ management of locoregionally advanced squamous cell carcinoma of the vulva. Am J Clin Oncol. 2013;36(4):415-22.
34. Scaunasu RV, Burcos T, Voiculescu S, Cozma CN, Horhoianu I, Balalau $\mathrm{C}$ et al. Role of anatomical and clinical prognostic factors in breast cancer assessment. Arch Balkan Med Union. 2014;49(3):273-5.

35. Paduraru M, Ponchietti L, Casas IM, Pereira J, Landaluce-Olavarria A, Mariani D. Emergency surgery and Limitation of therapeutic effort in relation to neurologic deterioration in elderly patients-a survey of European surgeons. J Mind Med Sci. 2017;4(2):142-7.

36. Jecan CR, Raducu L, Cozma C, Filip CI. Lower Lip Reconstruction After Excision of Advanced Squamous Cell Carcinoma-Case Report. RoJCED. 2015;2(2):128-31.

Cite this article as: Nahar K, Nahar N. Radical vulvectomy for a rare case of squamous cell carcinoma vulva: a case report. Int J Reprod Contracept Obstet Gynecol 2021;10:3215-22. 